\title{
On tourism teaching management in the context of information technology development and change
}

\author{
Yanjie ZHAN \\ Tonghua Normal University \\ Tonghua,Jilin,China \\ zhanyanjie@istp.cn
}

\begin{abstract}
From the perspective of human science, this paper uses natural science as the tools and methods to analyze student network behavior, considering providing college teaching and student management decision-making as the focal point and fundamental starting point. The utilization of authoritative and professional website Categories ODP, shows the students' interest in the Internet more accurately. There are many dimensions such as the basic information of students, IP address information of students, the information of college departments, time, the owned domain name, the card information and so on, which analyze the student network behavior in diversified ways. The charts using statistical analysis tools ProClarity to display, combining with the inherent properties of the user, and analyzing the campus network user data, to find the specific modes and laws of the student network user's behavior and form the valuable knowledge; to find the formation, existing features and changing regularity of the student network users' behavior, and raise the standards of related resources allocation; to find the features and laws of the student net users' behavior, analyze the psychological characteristics of students, and provide decision support for student management.
\end{abstract}

Keywords- tourism teaching; student management; teaching management

\section{INTRODUCTION}

Higher Tourism Education, as the cradle of the innovative spirit and talents, has lagged far behind in many aspects of training objectives and training mode. It needs reform. Tourism has a comprehensive, practical, multiplicity, economic and other characteristics. The traditional teachercentered teaching mode, one-way transfer of knowledge and skills in today's increasingly competitive talent, has been unable to meet the needs of the community. With the development of teaching and learning theory, especially the widely application of artificial intelligence, computer network technology and multimedia technology, has a profound impact on teaching practice and teaching research and exploration. Information-based teaching mode has gradually floated surface of the water in front of us.

Institutions of higher learning in China's higher education reform and development, teaching and research is always in the forefront of exploration, and gradually forms a series of areas of research which leads teaching philosophy, teaching methods and teaching management. As China's traditional teaching system is composed by three elements of the teachers, students and teaching materials, it is a one-way indoctrination teaching mode. This mode is one-sided emphasis on abstract understanding of the problem with the memory, to the neglect of its inspection and application of the theory, especially the more prominent class teaching and research in the humanities and social sciences in China. The rapid development of tourism and the competition has become increasingly fierce, and put forward new demands on the quality of our tourism professionals.

\section{TO ESTABLISH THREE-DIMENSIONAL TEACHING

PHILOSOPHY OF TRAVEL MANAGEMENT PROFESSIONAL

China's travel management professional education teaching is a thing of the past twenty years. Until the eighties of the last century in our country there is no real sense of the tourism industry. Therefore, China's tourism management teaching mode is to undertake the one-way education teaching mode which is teacher-centered and just teachers teach with students listen and remember. The essence of this kind of education is the knowledge of education, not smart education. It is a one-way propagation closed teaching traditional injection, which greatly limits the quality of tourism management students and creative ability.

\section{INFORMATION IS THE TRAINING NEEDS OF PROFESSIONAL COMPETENCE}

The professional competence of the modern tourism put forward higher requirements on travel services personnel. Tourism educational goals of secondary vocational education are to train the travel professional ability for the tourism, compound primary talent. The success of students in the tourism and related labor market trading tourism vocational education quality is the mark. The travel professional competence divides into the professional competence, ability and social competence. Professional competence is the basis of ability, directly related to the touring professional travel professional activities to be carried out. Master the method ability and social competence, but also in the general professional competence on the basis of the travel professional activities will get a multiplier effect. So foreign to this beyond the field of general professional competence outside professional activities carried out smoothly, and play a vital role in promoting career development the method ability and social ability, which known as the "key competencies".

Psychological research shows that the capacity development, capacity is a result of the activities. Activities require the ability activities applications and the opportunity 
to exercise a certain capacity. With richer and more solid activities, capacity development will be faster the stronger. "Activity" of tourism teaching highlighting the "peopleoriented" takes travel professional competence as the core, and prepare for students a lifelong learning and development.

\section{A. The inevitability of travel management information under the auspices of government}

Human society after the agricultural revolution and the industrial revolution, and now has entered a stage of the information revolution. The core of the information revolution is the representative of today's advanced productive forces --- IT, that is a huge expansion of the hightech base, including computer technology, telecommunications technology, radio and television technology, network technology, multimedia technology, database technology. The development of information technology produced varying degrees of impact on all aspects of human society, including tourism. According to forecasts, the number of users for online travel bookings in 2010 will reach 7.1 million. A huge potential market indicates a huge market opportunity. But at the same time, we see that the cultivation of online travel reservation market is a gradual process, and will show a stable development trend.

\section{B. intangibility and non-metastases of tourism products}

Because the intangibility of tourism products and nonmetastases characteristics decided tourism less involved physical transport, tourism activities which are mainly caused by the "flow" instead of "logistics", the application of e-commerce in the tourism industry of the physical distribution requirements is not high.

\section{Internal requirements tourism management information}

First, the tourism product is intangible and storage, not metastases. It has the characteristics of production and consumption at the same time. In the circulation of tourism market, the flow ones are tourists, but tourists' destination choice depends on only information. Tourists need convenient access to information channels and high-quality information services. Plenty of information not only can reduce the risk of tourists in tourist spending, better able to enhance the confidence of the tourists and the tourism products, increase the likelihood of purchase. Tourism operators and managers on product design and operating combination are based on market demand, under the guidance of the modern marketing concept. The link between tourism operators and managers is also fast. The smooth exchange of information aims to complete a variety of transactions and communication, exchange and process the tourism product, price, quality and convenience into other aspects of the information, along with the data flow and cash flow. Therefore, the information is an important link between tourism internal all links to links.

\section{ENTERPRISES WITH STUDENTS}

\section{A. Training high-quality talents}

As an enterprise, it is a priority to train high-quality personnel, especially in the hotel industry where employees turnover. Talent is one of the biggest bottlenecks to enterprise's development and promotion. Through the implementation of the model, the overall quality of the reserve talents has been greatly improved. Occupational clear thinking, the enterprise cultural identity, staff turnover will also get the corresponding control.

\section{B. students take the initiative to learn more consciously}

As a student, earlier familiar with the hotel makes them more motivated to learn more conscious, compared to the similar students. The students not only learn the operational skills, accept the hotel's corporate culture and more proactive foreign language learning, but also learn a second foreign language. At present, in addition to the classes outside the normal teaching program, it opened the spoken English and Japanese in the hotel, thus the students' enthusiasm for learning become generally high. Practice education system is to establish a scientific and feasible implementation of the model and the effect of protection. It is involved in practical education system to guide the process of practice teaching, monitoring, assessment and evaluation. Guiding force should be to establish a professional teachers and corporate technician backbone consisting of relatively stable guidance of teachers, to develop detailed guidance procedures and teacher evaluation rules. Specialized monitoring organization Composed of the relevant departments of the school teaching management departments and enterprises, monitor the process and the quality of the teaching, and to develop the practical ability to assess students based assessment rules, the practical performance of various courses for students at all stages, examination and evaluation, in order to ensure the smooth implementation of the practice teaching mode.

\section{Quality assessment of information teaching}

Assessment of the effect of the phase of teaching is both the outcome to market ability "test and one of the next stages of the market research. The inspection criteria indicate the satisfaction of tourism enterprises and the talent market to the graduates. That is to say the students' employment rate and job performance (see the tourism and teaching cycle system diagram).

\section{INFORMATION TECHNOLOGY UNDER THE CONDITIONS OF THE TOURISM MANAGEMENT TEACHING}

\section{A. The narrowness and hysterics of the practice of teaching in the teaching aspects of the arrangements}

Some colleges and universities in the tourism teaching link arrangements only pick out a few courses as skills training courses, only arrangements for graduation practice as a practical lesson, while other courses are basically on paper. Even if a very small percentage of these skill lessons skills training lesson share, graduation practice surface is relatively narrow, mostly service-learning, very few 
management internship, and internship mostly in the final year, usually internship and trainee is rare. The students with no probationary foundation make students practical knowledge very poor, flexible, which is extremely detrimental to master knowledge.

\section{B. multimedia teaching and tourism teaching}

Tourism disciplines have the integrated, space and multidisciplinary characteristics. The use of modern multimedia teaching methods can better give full play to the role of teaching received the best teaching results. Multimedia teaching in tourism teaching has the following positive significance.

\section{C. stimulate students' enthusiasm for learning human- computer cross, immediate feedback is the characteristics of multimedia teaching}

In the traditional mode of teaching, teaching content, teaching methods, teaching steps are teachers' prior arrangement. And the teacher's teaching methods taught by teachers in the classroom are just some abstract theory and methods, boring and difficult to understand. Only students' passive participation to the teachers teaching can make them greatly stimulate students' interest in learning, and enable students to have a strong desire to learn.

\section{D. focusing on tourism conventional basic education}

In tourism teaching, the school focuses on tourism conventional basic education, at the same time pays close attention to the students of the history of education and arts education, to foster the student's rich cultural heritage and historical insight, and to start from tourism psychology students, and to focus on health and tourism personality and quality of professional ethics. The school travel teaching has gotten rid of traditional classroom teaching mode, and they actively jointed the travel units across the country and moved to the classroom to the practice of tourism, implemented practical education, encourage students to participate in social practice, applied the theory into practice, digested theory in practice, and achieved a good teaching effect.

Through the application of the empirical formula tourism teaching, students' interest in travel professional learning and research have been significantly enhanced, and also deepen students' understanding of the value and significance of tourism in the concept of folklore, costumes, food, culture and habits. Teaching on the one hand by the empirical formula is conducive to the examination of the traditional theoretical perspectives, at the same time easy to find some new problem; the other hand, it enhances the knowledge of the authenticity, verifiability, and easier to learn and master students.

\section{E. Building network teaching platform in tourism management professional}

Network teaching mode by elements of teaching ideas, teaching objectives, technical environment, teaching strategies, and human-computer relationship, are based on the computer network for instructional media network learning environment, establishing teaching objectives to guide students in the network platform autonomous, collaborative, multi exploring learning mode. Building tourism management professional network teaching platform, three-dimensional teaching philosophy is based on tourism management professional, so as to cultivate the professional learners' innovation spirit and practical ability as a target rich network environment, then they can be more effectively carried out based on the resources, cooperation, study the problem, the process of learning, in order to achieve a threedimensional teaching model to be constructed.

\section{F. Effective development of three-dimensional teaching resources in tourism management professional}

Tourism Discipline is a new interdisciplinary discipline, psychology, aesthetics, ecology, economics, geography, management, culture, science, law and many other disciplines. The multidisciplinary reflects the diversity of the teaching resources, knowledge carriers, in addition to the paper medium teaching materials, electronic lesson plans, multimedia and network technology environment, e-books, CAI courseware, instructional videos and all the new knowledge of the carrier. Therefore, the textbooks, the media and the network are a three-dimensional teaching resources building efforts to increase these resources which is an important task of the effective development of tourism management professional three-dimensional teaching resources.

\section{THE URGENCY OF THE AGE OF TOURISM MANAGEMENT INFORMATION}

\section{A. The objective requirements of tourism management information}

Tourism operation in continuous flow and WAN Unicom premise, particularly emphasis on the overall co-ordination and sharing of resources. Travel management efficiency and benefits of growth cannot be separated the organic cooperation in the global. It shows that the tourism industry involved in a wide range of cooperation, associated strong industry, tourism internal between the constituent elements, as well as tourism and other industries must coherence.

\section{B. Internal requirements of tourism management information}

First, the tourism product is intangible and storage, not metastases. It has the characteristics of production and consumption at the same time. Tourism operators and managers on product design and operating combination is based on market demand, under the guidance of the modern marketing concept. The link between tourism operators and managers is also fast. Smooth exchange of information aims to complete a variety of transactions and communication. Exchange and processing is the price, quality, convenience, accessibility competitiveness of the tourism product. IT is an indispensable support. Second, the tourism industry is very fragile and vulnerable. It is fluctuate to macro and micro environment in a variety of natural, political and economic factors. Then effective access to information to assist the scientific decision-making is especially important. Third, 
suitability of the tourism industry to carry out e-commerce makes the use of shared resources quite prominent in the tourism industry. Since the development of e-commerce in the ascendant, carrying out tourism e-commerce can reduce the cost of access to information and passed to improve the competitiveness of their products, but IT is still an indispensable support.

\section{CONCLUSIONS}

Operability of tourism professional combining school social practice with school video education, simulation test is very strong and emphasis on practice with teaching. However, due to objective reasons, many university tourism education professional characteristics embodied inadequately, and some institutions were even behind closed doors, school, and had little contact with tourism enterprises with their own lack of modern equipment and conditions, so that the students can not achieve the theoretical with practice. They can only learn from a book to some abstract theory of knowledge. Innovative and practical ability of students is not effective development and exercise. In the information technology environment, you can take advantage of the multimedia classroom practice courseware either enable students to acquire specialized knowledge, but also to advance understanding of the basic essentials of actionable test and note, greatly improve the effect of practice teaching, can also try to reduce the incidence of accidents in the internship process.

\section{ACKNOWLEDGEMENT}

Foundation item: 2013 year project of the education of Jilin province "Twelfth Five Year Plan", project number: GH13519

\section{References}

[1] Sheng Zhengfa. China Tourism Higher Education [J]. Journal of Xiangtan Teachers College ( SOCIAL SCIENCE EDITION ). 2006 (01).

[2] Qu wataru. Guangxi tourism higher education problems and Countermeasures in the construction of [J]. Travel forum. 2010 (03).

[3] Feng Ping, Yin jian. Discussion on Higher Tourism Vocational case teaching mode [J]. Exam week. 2007(25).

[4] Liu Junping. How to change the travel professional teaching mode [J]. Modern rural science and technology. 2010(06). 